\title{
Germinação e descrição morfológica de plântula de Guazuma ulmifolia Lam. em diferentes pHs
}

Guazuma ulmifolia Lam. é uma espécie de rápido crescimento que permite cobrir o solo rapidamente e frequentemente utilizada em programas de restauração florestal, entretanto, há poucos estudos sobre esta espécie, e a falta de informação pode resultar em inssucesso de implantação de programas de restauração florestal. Desse modo objetivou-se neste estudo avaliar a influência do pH sobre a germinação e desenvolvimento de plântulas, e realizar a descrição morfológica do processo de germinação até o desenvolvimento de plântulas através de ilustrações de espécie Guazuma ulmifolia. No teste de germinação utilizou-se soluções aquosas com valores de $\mathrm{pHs}(2,0 ; 3,0 ; 4,0 ; 5,0 ; 6,0 ; 7,0 ; 8,0 ; 9,0 ; 10,0$ e 11,0) para o umedecimento de acordo com cada tratamento, cujas soluções foram reguladas utilizando hidróxido de sódio $(\mathrm{NaOH})$ e ácido clorídrico $(\mathrm{HCl})$. Determinou-se a porcentagem de germinação final, o índice de velocidade de germinação, e variáveis morfométricas das plântulas (comprimento da parte aérea, radícula, comprimento total, espessura do coleto, e peso individual). Realizou-se ilustração e a descrição dos três estádios de desenvolvimento da plântula (Fase I: plântulas com emissão de radícula; Fase II: plântulas apresentando os cotilédones; Fase III: plântulas apresentando primeiro par de folhas). $\mathrm{O} \mathrm{pH}$ não interferiu na porcentagem de germinação, índice de velocidade de germinação e espessura do coleto, e apresentou maiores valores nas demais variáveis analisadas na faixa de $\mathrm{pH} 4$ a 11. A germinação é do tipo epígea fanerocotiledonar, e as características observadas nas fases de desenvolvimento das plântulas podem auxiliar como norteadores em identificação de espécies em fase de plântulas no campo, e contribuir na distinção de plântulas normais com as anormais.

\section{Germination and morphological description of Guazuma ulmifolia Lam. Seedling at different pHs}

\begin{abstract}
Guazuma ulmifolia Lam. is a species of fast growth that allows covering the ground quickly and often used in forest restoration programs, however, there are few studies on this species, and the lack of information can result in failure of implementation of forest restoration programs. Thus, the objective of this study was to evaluate the influence of $\mathrm{pH}$ on germination and seedling development, and to perform the morphological description of the germination process until the development of seedlings through illustrations of Guazuma ulmifolia species. In the germination test, aqueous solutions with $\mathrm{pH}$ values (2.0; $3.0 ; 4.0 ; 5.0 ; 6.0 ; 7.0$ $8.0 ; 9.0 ; 10.0$ and 11.0) were used for wetting according to each treatment, whose solutions were regulated using sodium hydroxide (NaOH) and hydrochloric acid $(\mathrm{HCl})$. The final germination percentage, germination speed index, and morphometric variables of the seedlings (aerial part length, radicle, total length, collar thickness, and individual weight) were determined. We illustrated and described the three seedling development stages (Stage I: seedlings with radicle emission Stage II: seedlings presenting the cotyledons; Stage III: seedlings presenting the first pair of leaves). The pH did not interfere in the germination percentage, germination speed index and collar thickness, and showed higher values in the other variables analyzed in the $\mathrm{pH}$ range 4 to 11 . The germination is of the phanerocotyledonary-epigeal type, and the characteristics observed in the development phases of the seedlings may help to identify species in the seedling phase in the field, and contribute to the distinction between normal and abnormal seedlings.
\end{abstract}

Keywords: Southern Amazon; Direct seeding; Forest seed; Illustration.

Topic: Ciências Florestais

Reviewed anonymously in the process of blind peer.

Mariane Kaori Sasaya (iD)

Universidade do Estado de Mato Grosso, Brasil

http://lattes.cnpq.br/0746690858035832

http://orcid.org/0000-0002-9159-4953

marianekaori@gmail.com

Roseline da Silva Melo (iD

Universidade do Estado de Mato Grosso, Brasil

http://lattes.cnpq.br/9874475151832297

http://orcid.org/0000-0003-4841-2541

melloroseline@gmail.com

Antonio Gomes do Nascimento Júnior (10)

Universidade do Estado de Mato Grosso, Brasil

http://lattes.cnpq.br/7745665614882395

http://orcid.org/0000-0002-0941-9882

antonio gomesjunior@hotmail.com

d

DOI: 10.6008/CBPC2179-6858.2021.007.0007
Received: 03/07/2021

Approved: 27/07/2021

\author{
Mateus dos Santos \\ Universidade do Estado de Mato Grosso, Brasil \\ http://lattes.cnpq.br/4251187520937013 \\ http://orcid.org/0000-0003-2479-8507 \\ mateus furlaneto@hotmail.com \\ Laura Araujo Sanches \\ Universidade do Estado de Mato Grosso, Brasil \\ http://lattes.cnpq.br/0130822318136543 \\ http://orcid.org/0000-0002-7829-8842 \\ laura araujo 555@hotmail.com \\ Juliana Garlet (iD) \\ Universidade do Estado de Mato Grosso, Brasil \\ http://lattes.cnpq.br/5797330535113543 \\ http://orcid.org/0000-0002-0791-7060 \\ julianagarlet@unemat.br
}

\section{Referencing this:}

SASAYA, M. K.; MELO, R. S.; NASCIMENTO JUNIOR, A. G.; SANTOS, M.; SANCHES, L. A.; GARLET, J.. Germinação e descrição morfológica de plântula de Guazuma ulmifolia Lam. em diferentes pHs. Revista Ibero Americana de Ciências Ambientais, v.12, n.7, p.72-80, 2021. DOI: http://doi.org/10.6008/CBPC2179-6858.2021.007.0007 


\section{INTRODUÇÃO}

O Brasil detém área extensa ocupada pela floresta tropical e consequentemente apresenta grande biodiversidade. No entanto, ações antrópicas têm levado a diminuição significativa de áreas florestais nativas. Isso tem ocorrido pela elevada demanda de madeiras pelo mercado consumidor, que resultou na exploração de florestas nativas sem planejamento, e pela abertura de novas áreas para agricultura e pecuária (COPERTINO et al., 2019). Diante deste cenário, a cada ano aumenta a necessidade de realizar recomposição de florestas utilizando espécies nativas. A restauração florestal é uma atividade multidisciplinar que concilia conhecimentos sobre Ecologia, Botânica, Silvicultura, Ciência do Solo, Economia e entre outros, e tem como objetivo reestabelecer funções do ecossistema e recuperar diversos componentes da biodiversidade original que foram perdidas (CHAZDON, 2008; GROSSNICKLE et al., 2017).

Uma das formas de plantio mais utilizadas nos projetos de restauração atualmente é a semeadura direta, que consiste na utilização de sementes de espécies florestais diretamente no solo da área que se pretende reflorestar com intuito de promover o recobrimento do solo. Sendo que essa técnica possibilita realizar restauração ecológica com várias espécies devido à facilidade de criar misturas de espécies em comparação com o plantio convencional, assim promovendo maior diversidade e densidade de plantas (AGUIRRE et al., 2015; GROSSNICKLE et al., 2017). Sendo o Código Florestal (Lei no12.651/2012) (BRASIL, 2012) atualmente recomenda-se realizar plantios com diversas espécies nativas escolhidas de acordo com suas aptidões ecológicas. E dentre as espécies florestais nativas comumente empregadas em reflorestamento ou programas de restauração em município de Alta Floresta-Mato Grosso destaca-se a Guazuma ulmifolia devido seu rápido crescimento que permite cobrir o solo rapidamente (LORENZI, 2009).

O sucesso do estabelecimento das plantas quando efetuada a semeadura direta é dependente do estado fisiológico das sementes a serem utilizadas envolvendo aspectos sanitários, genéticos e fisiológicos. Bem como fatores ambientais e edáficos onde a semente está inserida, sendo estes: umidade, regime de temperatura, nutrientes e $\mathrm{pH}$. Tais fatores podem influenciar diretamente ou indiretamente na germinação que consequentemente interferem na capacidade de estabelecimento e no desenvolvimento da planta (PEREIRA et al., 2002; AIMI et al., 2016).

Assim, para aumentar a eficiência da semeadura direta, torna-se de grande importância a obtenção de informações básicas sobre as espécies a serem utilizadas, escolhendo espécies adequadas para cada situação que se encontra a campo. Pois, a germinação de sementes, e o desenvolvimento das plântulas são influenciadas por diversos fatores incluindo os edafoclimáticos, refletindo em respostas variadas de acordo com a condição que as sementes foram submetidas. Dentre estes fatores edafoclimáticos que podem causar efeitos negativos aos cultivos destaca-se o pH, pois muitos plantios para fins de restauração são realizados em solos sem correção de nutrição e pH. E o pH em níveis mais extremos atua como fator limitante na germinação e estabelecimento de plantas no campo. No entanto o comportamento das sementes varia de acordo com as espécies, pois algumas espécies apresentam preferência pelos solos ácidos, e outras pelos solos alcalinos (TUDELA-ISANTA et al., 2018). 
$\mathrm{O}$ pH do solo tem papel crucial na assimilação de nutrientes pelas plantas. Sendo que solos ácidos que são comumente encontrados no Brasil, de modo predominante nestes, estão as formas trocáveis de alumínio $\left(\mathrm{Al}^{3+}\right)$ na solução do solo quando este está abaixo de pH 5. Desse modo, limita o desenvolvimento do sistema radicular e consequentemente, a absorção de nutrientes. Além disso, a variação de pH afeta a disponibilidade de macronutrientes e micronutrientes no solo que são indispensáveis para um bom desenvolvimento da planta (RODRIGUES et al., 2004; VARGAS et al., 2019; BRIGNOLI et al., 2020).

Cabe ressaltar, que existem poucos estudos sobre o efeito do $\mathrm{pH}$ na germinação para espécies florestais nativas, incluindo a Guazuma ulmifolia. Essa falta de informações pode resultar em insucessos na implantação de programas de restauração florestal, por empregar as espécies em locais com condições edafoclimáticas inadequadas (SILVA et al., 2017).

A falta de informação de espécies florestais nativas também se aplica em relação aos estudos morfológicos de plântulas. Contudo, o estudo morfológico de sementes e plântulas nos estágios iniciais de desenvolvimento contribui para melhorar o conhecimento do processo reprodutivo das espécies vegetais, servindo de subsídio para os plantios e na identificação destas espécies em condições naturais na floresta. E a caracterização de plântulas no campo contribui no planejamento e tratamentos silviculturais assim possibilitando o sucesso na implantação de plantios florestais (GUERRA et al., 2006).

Assim, objetivou-se neste estudo avaliar a influência do pH sobre a germinação e desenvolvimento de plântulas, e realizar a descrição morfológica do processo de germinação até o desenvolvimento de plântulas por meio de ilustrações da espécie Guazuma ulmifolia Lam.

\section{MATERIAIS E MÉTODOS}

\section{Teste de Germinação}

O experimento foi conduzido nos laboratórios do CEPTAM (Centro de Pesquisa e Tecnologia da Amazônia Meridional) no Campus II da Universidade do Estado de Mato Grosso (UNEMAT), campus de Alta Floresta. As sementes utilizadas foram fornecidas pelo Instituto Centro de Vida (ICV) localizado no município de Alta Floresta - MT, sendo a mesma proveniente de coleta realizada no ano de 2019.

O teste de germinação foi realizado de acordo com as recomendações da Regra Brasileira de Sementes (RAS) (BRASIL, 2009) e o documento do Mapa (Ministério da Agricultura Pecuária e Abastecimento) referente a análise de sementes florestais (BRASIL, 2013).

Devido a semente de Guazuma ulmifolia apresentar dormência, primeiramente realizou-se a imersão em água a $90^{\circ} \mathrm{C}$ fora da fonte de calor e deixando a mesma água por 24 horas com intuito de superação de dormência conforme recomendações de documento oficial para análise de sementes florestais (BRASIL, 2013).

Após o processo de superação de dormência, a semente passou pela assepsia para remoção de impurezas e evitar proliferação de fungos. A assepsia foi realizada por meio de imersão de semente em solução com detergente (cinco gotas de detergente em $100 \mathrm{~mL}$ de água) durante dez minutos, e 
posteriormente estas foram lavadas em água corrente para a remoção destas substâncias. Em seguida, realizou-se semeadura das sementes em sobre papel, sendo efetuada de modo que as sementes ficassem sobrepostas de duas folhas de papel Germitest $($ ) umedecidas com solução na proporção de duas vezes o peso do papel seco em caixas plásticas do tipo Gerbox (BRASIL, 2013).

Após a montagem, os tratamentos foram mantidos em câmara de germinação tipo Biochemical Oxigen Demand (BOD), em temperatura constante de $30{ }^{\circ} \mathrm{C}$, com fotoperíodo de 12 horas, utilizando lâmpadas fluorescentes. Durante todo o tempo do experimento, quando necessário foi realizado o umedecimento do substrato através de soluções com pH regulados para cada tratamento de modo que os substratos ficassem suficientemente úmidos para proporcionar às sementes umidade necessária para sua germinação (BRASIL, 2009).

Durante o experimento, todos os umedecimentos nos testes de germinação foram efetuados por meio de soluções aquosas com valores de pHs de acordo com cada tratamento, sendo eles: 2,0; 3,0; 4,0; 5,0; 6,$0 ; 7 ; 0 ; 8,0 ; 9,0 ; 10,0$ e 11,0. Para regular o pH nos valores referidos acima, adicionou-se a água destilada hidróxido de sódio $(\mathrm{NaOH})$ para elevar o mesmo, e ácido clorídrico ( $\mathrm{HCl}$ ) para acidificar, sendo o pH medido com auxílio de um pHmetro de bancada (Medidor de pH TEC-2), visando estabelecer os níveis desejados.

A determinação da porcentagem de sementes germinadas (germinação final), foi realizada pela contagem do número de plântulas normais da espécie em análise, conforme a RAS (BRASIL, 2009). A qual define que as plântulas normais são aquelas que possuem todas as suas estruturas essenciais bem desenvolvidas, completas, proporcionais e sadias (sistema radicular, parte aérea, gemas terminais, e cotilédones), com potencial para a continuação do seu desenvolvimento e dar origem a plantas normais, quando desenvolvidas sob condições favoráveis.

No presente experimento, os valores percentuais de germinação final de plântulas normais (GF) foram obtidos por meio da Equação 1:

$$
G F=\frac{\left(\sum n \text { o sementes germinadas } * 100\right)}{n^{0} \text { sementes por repetição }} \text { Equação } 1
$$

O índice de velocidade de germinação (IVG) foi realizado conjuntamente com o teste de germinação, o qual foi calculado por meio da equação proposta por Maguire (1962), Equação 2:

$$
I V G=\frac{G 1}{N 1}+\frac{G 2}{N 2}+\frac{G 3}{N 3} \ldots+\frac{G n}{N n} \text { Equação } 2
$$

Sendo: $G 1, G 2, G 3, \ldots, G n$ = número de plântulas computadas na primeira, segunda, terceira e última contagem; N1, $\mathrm{N} 2, \mathrm{~N} 3, \ldots, \mathrm{Nn}=$ número de dias da semeadura à primeira, segunda, terceira e última contagem. Com o objetivo de analisar a diferenciação do desenvolvimento de plântulas em respostas aos diferentes pHs, foi realizada a análise morfométrica de plântulas germinadas, efetuando medições de comprimento da parte aérea, raiz, comprimento total, com o auxílio de régua graduada em $\mathrm{mm}$, e a espessura do coleto determinada por meio de paquímetro digital. A massa úmida individual das plântulas foi obtida com auxílio de balança de precisão $(0,0001 \mathrm{~g})$.

O teste de germinação foi conduzido no delineamento inteiramente casualizado (DIC) com quatro repetições, utilizando 25 sementes por repetição, totalizando 100 sementes para cada tratamento. Para verificação da normalidade dos dados utilizou-se o teste de Shapiro-Wilk, e devido à anormalidade dos 
mesmo para germinação e parâmetros morfométricos, realizou-se testes não paramétricos. Assim, a análise dos dados foi realizada com o teste de Kruskal-Wallis, seguido do teste post-hoc de Dunn, com ajuste de pvalor tipo Bonferroni $(p<0,05)$. A análise dos dados foi realizada com o auxílio do pacote dun.test no software R versão 4.0.2 (R DEVELOPMENT CORE EQUIPE, 2020).

\section{Descrição e ilustração morfológica de plântula}

Para as descrições e ilustrações morfológicas do desenvolvimento das plântulas, foram utilizadas plântulas provenientes dos testes de germinação umedecidas com solução de pH 7, pois a Regra de Análise de Sementes (RAS) (2009), recomenda a utilização de água com pH de 6,0-7,5 para umedecimento nos testes de germinação.

Para a ilustração escolheu-se as plântulas normais mais vigorosas. Isto é, as plantas que possuíam todas as suas estruturas essenciais bem desenvolvidas, completas, proporcionais e sadias (sistema radicular, parte aérea, gemas terminais e cotilédones) e descrevendo os seguintes estádios de desenvolvimento: Fase I: plântulas com emissão de radícula; Fase II: plântulas apresentando os cotilédones; Fase III: plântulas apresentando primeiro par de folhas. As ilustrações foram confeccionadas à mão, e após digitalizadas e editadas por meio de software GIMP versão 2.10.22; e FireAlpaca versão 1.9.0.

\section{RESULTADOS E DISCUSSÃO}

Na Tabela 1 estão apresentados os valores médios de germinação final, índice de velocidade de germinação e parâmetros morfométricos de plântulas de Guazuma ulmifolia em diferentes pHs.

Tabela 1: Média de germinação final, índice de velocidade de germinação e morfometria de plântulas em diferentes faixas de pH para: Guazuma ulmifolia.

\begin{tabular}{llllllll}
\hline \multicolumn{7}{l}{ Guazuma ulmifolia } & \multicolumn{7}{l}{$l$} \\
\hline $\mathrm{pH}$ & $\mathrm{GF} *$ & $\mathrm{IVG}$ & $\mathrm{CA}$ & $\mathrm{CR}$ & $\mathrm{CT}$ & $\mathrm{EC}$ & Peso \\
\hline 2 & $69,0 \mathrm{a}$ & $2,3 \mathrm{a}$ & $20,4 \mathrm{ab}$ & $6,7 \mathrm{~b}$ & $27,3 \mathrm{~b}$ & $0,78 \mathrm{a}$ & $16,0 \mathrm{c}$ \\
3 & $82,0 \mathrm{a}$ & $2,5 \mathrm{a}$ & $20,2 \mathrm{~b}$ & $11,6 \mathrm{ab}$ & $31,3 \mathrm{ab}$ & $0,8 \mathrm{a}$ & $19,0 \mathrm{ab}$ \\
4 & $80,0 \mathrm{a}$ & $3,1 \mathrm{a}$ & $21,2 \mathrm{ab}$ & $11,9 \mathrm{ab}$ & $33,2 \mathrm{ab}$ & $0,8 \mathrm{a}$ & $19,0 \mathrm{ab}$ \\
5 & $81,0 \mathrm{a}$ & $3,8 \mathrm{a}$ & $24,53 \mathrm{ab}$ & $12,2 \mathrm{ab}$ & $34,3 \mathrm{ab}$ & $0,8 \mathrm{a}$ & $23,0 \mathrm{ab}$ \\
6 & $78,0 \mathrm{a}$ & $3,0 \mathrm{a}$ & $23,2 \mathrm{ab}$ & $12,2 \mathrm{ab}$ & $35,4 \mathrm{ab}$ & $0,8 \mathrm{a}$ & $30,0 \mathrm{a}$ \\
7 & $89,0 \mathrm{a}$ & $4,0 \mathrm{a}$ & $23,2 \mathrm{ab}$ & $12,4 \mathrm{ab}$ & $34,5 \mathrm{ab}$ & $0,8 \mathrm{a}$ & $24,0 \mathrm{ab}$ \\
8 & $85,0 \mathrm{a}$ & $3,7 \mathrm{a}$ & $22,9 \mathrm{ab}$ & $11,9 \mathrm{ab}$ & $34,2 \mathrm{ab}$ & $0,7 \mathrm{a}$ & $20,0 \mathrm{ab}$ \\
9 & $80,0 \mathrm{a}$ & $4,1 \mathrm{a}$ & $27,1 \mathrm{a}$ & $13,0 \mathrm{a}$ & $38,6 \mathrm{a}$ & $0,7 \mathrm{a}$ & $25,0 \mathrm{~b}$ \\
10 & $82,0 \mathrm{a}$ & $3,5 \mathrm{a}$ & $26,1 \mathrm{a}$ & $9,2 \mathrm{ab}$ & $33,8 \mathrm{ab}$ & $0,7 \mathrm{a}$ & $23,0 \mathrm{ab}$ \\
11 & $70,0 \mathrm{a}$ & $1,6 \mathrm{a}$ & $21,6 \mathrm{ab}$ & $10,2 \mathrm{ab}$ & $33,3 \mathrm{ab}$ & $0,6 \mathrm{a}$ & $24,0 \mathrm{ab}$ \\
\hline \multirow{2}{*}{$\mathrm{W}$} & $\mathrm{W}=0,95$ & $\mathrm{~W}=0,96$ & $\mathrm{~W}=0,99$ & $\mathrm{~W}=0,99$ & $\mathrm{~W}=0,99$ & $\mathrm{~W}=0,99 ;$ & $\mathrm{W}=0,97$ \\
& $\mathrm{p}=0,13$ & $\mathrm{p}=0,23$ & $\mathrm{p}=0,43$ & $\mathrm{p}=0,01$ & $\mathrm{p}=0,38$ & $\mathrm{p}=0,07$ & $\mathrm{p}=1,52^{\mathrm{e}-06}$ \\
$\mathrm{KW}$ & $\mathrm{p}=0,05$ & $\mathrm{p}=0,06$ & $\mathrm{p}=1,15^{\mathrm{e}-11}$ & $\mathrm{p}<2,2^{\mathrm{e}-16}$ & $\mathrm{p}<2,2^{\mathrm{e}-16}$ & $\mathrm{p}=0,05$ & $\mathrm{p}<2,2^{\mathrm{e}-16}$ \\
\hline
\end{tabular}

As médias seguidas pela mesma letra minúscula na coluna para cada espécie avaliada não diferem estatisticamente entre si pelo teste de Dunn -Bonferroni $(p<0,05)$.

$\mathrm{CA}=$ Comprimento da Parte aérea $(\mathrm{mm}) ; \mathrm{CR}=$ Comprimento de radícula $(\mathrm{mm}) ; \mathrm{CT}=$ Comprimento Total $(\mathrm{mm}) ; \mathrm{EC}=$ Espessura de Coleto $(\mathrm{mm}) ; \mathrm{P}=\mathrm{Peso}(\mathrm{mg})$; $\mathrm{GF}=$ porcentagem de germinação final; IVG= Índice de Velocidade de Germinação, W= Teste de Shapiro-Wilk; KW= Teste de Kruskal-Wallis.

Na Tabela 1, nota-se que não houve diferença entre os pHs analisados para as variáveis de germinação (porcentagem de germinação e o índice de velocidade de germinação), e para a espessura de 
coleto. No comprimento de parte área, apresenta-se diferença apenas entre o pH 3 (menor média) para os pHs 9 e 10.

Os valores de $\mathrm{pH}$ menores que 3 e superiores a 8,0 comumente tem sido descrito como inibidores do processo germinativo, pois para condições que o pH esteja fora desse intervalo, altas concentrações de $\mathrm{H} \mathrm{e}$ $\mathrm{OH}$ (H=Hidrogênio; $\mathrm{OH=Hidroxila)} \mathrm{podem} \mathrm{ser} \mathrm{diretamente} \mathrm{tóxicos} \mathrm{às} \mathrm{plantas} \mathrm{(JANSEN} \mathrm{et} \mathrm{al.,} \mathrm{1953).}$

Yamauti et al. (2012) e Bandeira et al. (2018) avaliando a influência de diferentes níveis de pH na germinação de sementes de Senna obtusifolia (L.) H. S. Irwin \& Barneby (Fabaceae), e Synedrellopsis grisebachii Hieron. \& Kuntze (Asteraceae), obtiveram germinação em pHs de 3 a 11. Segundo os autores, a maior germinação ocorreu em pH 3 e menor em pH 11 sendo ainda que o aumento do nível de pH causou um decréscimo na porcentagem de germinação e no índice de velocidade de germinação das espécies analisadas pelos autores.

Os pHs extremos também podem causar efeitos negativos no desenvolvimento de plântulas. Gilani et al. (2021), observaram diminuição do comprimento de radícula e hipocótilo nos tratamentos que foram umedecidos com solução de pH 2,5 para quatro espécies arbóreas (Cunninghamia lanceolata (Lamb.) Hook, Fokienia hodginsii (Dunn) A. Henry \& H H. Thomas, Pinus massoniana (Lamb.) e Phoebe zhennan (Hemsl.).). Ünlü et al. (2010), também observaram para a espécie Capsicum annuum L. diminuição nos parâmetros morfométricos especialmente no pH 3, no qual afetou a formação de raiz lateral. Estes autores afirmam que más formações radiculares induzidas por hidrogênio, podem interferir na absorção e no transporte de nutrientes o que prejudica diretamente o estabelecimento e a sobrevivência das plantas.

No entanto, nem sempre essas faixas de pH (menores que 3 e superiores a 8) são prejudiciais às plantas, pois cada espécie possui faixas de limites de tolerância distintos em relação ao pH (SHOEMAKERL et al., 1990). Existem casos que o pH não é um fator restritivo e que causa efeito negativo sobre a germinação, como foi observado para a Guazuma ulmifolia no presente estudo. Caso semelhante foi relatado por Gilani et al. (2021), pois estes autores avaliaram o efeito de pH sobre a germinação de Pinheiro-chinês (Cunninghamia lanceolata), nos níveis de pHs de 2.5, 3.5, 4.5 e 5.5. No entanto, os valores de pHs referidos não chegaram a afetar negativamente a germinação, e a massa úmida de radícula desta espécie. E ainda estes mesmos autores afirmam que dependendo da espécie, o efeito do $\mathrm{pH}$ pode favorecer a germinação por atuar na quebra de dormência das sementes que apresenta tegumento espesso como a espécie Pinus massoniana.

Em relação a espessura do coleto (Tabela 1), não apresentou nenhuma diferenciação entre os pHs diferentemente dos comprimentos das partes de plântulas que foram mais sensíveis em relação à variação do pH. Segundo Vanzolini et al. (2007), o comprimento de plântulas, é mais sensível para classificar lotes com diferenças de qualidade, e consequentemente influências do meio no processo de germinação e desenvolvimento de plântulas. Para Mandić et al. (2011), que avaliaram o efeito de pH na germinação e no crescimento de trevo vermelho das variedades K-17 e Kolubara, os pHs de 4,0 a 7,0 não chegaram a afetar a germinação para ambas as variedades. Porém, quanto a radícula os autores observaram maior comprimento no pH 5 que no pH 7, apresentando diferenciação estatística entre estes pHs. 
Considerando que na região do município de Alta Floresta-MT, o pH do solo tem apresentado valores variando de 4,41 a 5,78. Com caracterização de pHs de 4,41 a 5,78 em áreas de floresta nativa, pH de 5,49 sob área de preservação permanente degradada, e pH de 5,75 em área de pastagem (FIGUEIRA, 2015; NEVES, 2018). Referindo-se da Guazuma ulmifolia que não apresentou interferência do pH na porcentagem de germinação, índice de velocidade de germinação e espessura do coleto, e constatou-se que na faixa de pH 4 a 10 a espécie apresentou os maiores valores nas demais variáveis analisadas. Pode-se inferir que o pH não é um fator limitante para a germinação e possivelmente apresenta alto potencial para serem utilizadas no campo em projetos de restauração florestal com semeadura direta, em solos sem correção de pH na região norte de Mato Grosso, na Amazônia Meridional.

\section{Descrição e ilustração morfológica de plântula}

A Figura 1 demonstra as fases de desenvolvimento da espécie Guazuma ulmifolia.
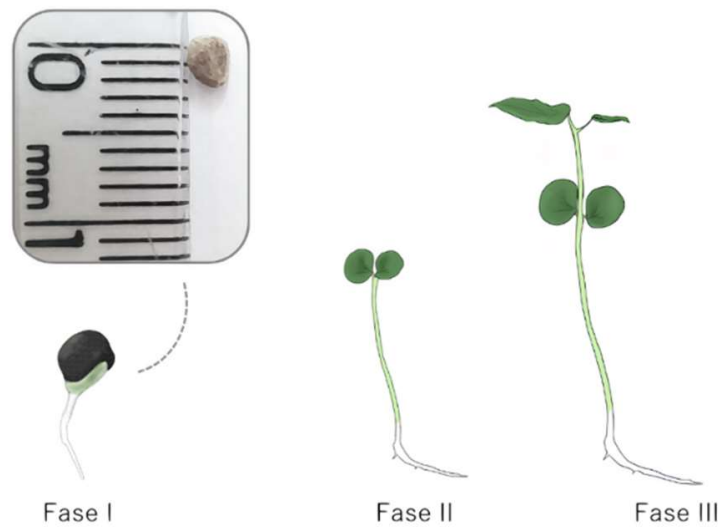

Figura 1: Ilustração de desenvolvimento pós-seminal da espécie Guazuma ulmifolia. Sendo: Fase I: plântulas com emissão de radícula; Fase II: plântulas apresentando os cotilédones; Fase III: plântulas apresentando primeiro par de folhas.

As sementes de Guazuma ulmifolia tem formato arredondado, com coloração acinzentada e quando umedecidas passam a apresentar uma coloração escura com camada exterior gelatinosa e transparente. Após quatro dias da semeadura, verificou-se o início de emissão de radícula, ocorrendo germinação do tipo epígea fanerocotiledonar, o hipocótilo é cilíndrico, herbáceo, de coloração verde-clara. O surgimento dos cotilédones ocorreu após o sétimo dia da semeadura, sendo que os cotilédones apresentam coloração verdeclara, porém um pouco mais escuras que o hipocótilo. Após o desenvolvimento do hipocótilo, ocorre o surgimento das primeiras folhas simples. Sendo essas características também foram observadas por Paiva Sobrinho et al. (2008).

\section{CONCLUSÕES}

Guazuma ulmifolia não apresentou interferência do pH na porcentagem de germinação, índice de velocidade de germinação e espessura do coleto, no entanto, constatou-se que na faixa de pH 4 a 10 a espécie apresentou os maiores valores nas demais variáveis analisadas.

As características observadas nas três fases de desenvolvimento das plântulas, podem auxiliar como 
norteadores em identificação de espécies em fase de plântulas no campo, bem como contribuir na distinção de plântulas normais com as anormais.

\section{REFERÊNCIAS}

AGUIRRE, A. G.; LIMA, J. T.; TEIXEIRA, J.; GANDOLFI, S.. Potencial da semeadura direta na restauração florestal de pastagem abandonada no município de Piracaia, SP, Brasil. Hoehnea, v.42, n.4, p.629-64. 2015. DOI: http://doi.org/10.1590/2236-8906-04/RAD/2015

AIMI, S. C.; ARAUJO, M. M.; MUNIZ, M. F. B.; WALKER, C.. Teste de sanidade e germinação em sementes de Cabralea canjerana (Vell.) Mart. Ciência Florestal, v.26, n.4, p.13611370, 2016. DOI: http://doi.org/10.5902/1980509825155

BANDEIRA, S. B.; EDEIROS, G. H.; SILVA, A. A.; SARAIVA, I. R.; SOUZA, P. B.; LEMUS, E. E. A.. Ecofisiologia da germinação de fedegoso Senna obtusifolia (L.) H. S. Irwin \& Barneby. Colloquium Agrariae, v.14, n.1, p.16-25, 2018. DOI: http://doi.org/10.5747/ca.2018.v14.n1.a186

BRASIL. Ministério da Agricultura, Pecuária e Abastecimento. Regras para Análises de Sementes. Brasília: MAPA, 2009.

BRASIL. Ministério da Agricultura, Pecuária e Abastecimento. Instruções para análise de sementes de espécies florestais. Brasília: MAPA, 2013.

BRASIL. Lei n. 12.651, de 25 de maio de 2012. Dispõe sobre a proteção da vegetação nativa; altera as Leis nos 6.938 , de 31 de agosto de 1981, 9.393, de 19 de dezembro de 1996, e 11.428, de 22 de dezembro de 2006; revoga as Leis nos 4.771 , de 15 de setembro de 1965 , e 7.754 , de 14 de abril de 1989, e a Medida Provisória o 2.166-67, de 24 de agosto de 2001; e dá outras providências. Brasília: DOU, 2012.

BRIGNOLI, F. M.; SOUZA JUNIOR, A. A.; GRANDO, D. L.; MUMBACH, G. L.; PAJARA, F. F. D.. Atributos biométricos da soja influenciados pelo nível de $\mathrm{pH}$ do solo. Revista Científica Rural, v.22, n.2, p.13-28, 2020. DOI: http://doi.org/10.30945/rcr-v22i2.3211

CHAZDON, R. L.. Beyond deforestation: restoring forests and ecosystem services on degraded lands. Science, v.320, n.5882, p.1458-1460. 2008. DOI:

http://doi.org/10.1126/science.1155365

COPERTINO, M.; PIEDADE, M. T. F.; VIEIRA, I. C. G.; BUSTAMANTE, M.. Desmatamento, fogo e clima estão intimamente conectados na Amazônia. Ciência e Cultura, v.71, n.4, p.4-5, 2019. DOI: http://dx.doi.org/10.21800/2317-66602019000400002

FIGUEIRA, J. C. C.. Atributos químicos e físicos dos solos sob sistemas agroflorestais em áreas de preservação permanente no município de Alta Floresta. Dissertação (Mestrado em Biodiversidade e Agroecossistemas Amazônicos) - Universidade do Estado de Mato Grosso, Alta Floresta, 2015.

GILANI, M. M.; TIGABU, M.; LIU, B.; FAROOQ, T. H.; RASHID, M. H. U.; RAMZAN, M.; MA, X.. Seed germination and seedling emergence of four tree species of southern China in response to acid rain. Journal of Forestry Research, v.32, n.1, p.471-481, 2021. DOI: http://doi.org/10.1007/s11676020-01102-0

GROSSNICKLE, S. C.; IVETIĆ, V.. Direct seeding in reforestation: a field performance review. Reforesta, v.4, n.1, p.94-142, 2017. DOI:

http://doi.org/10.21750/REFOR.4.07.46

GUERRA, M. E. C.; MEDEIROS FILHO, S. M.; GALLÃO, M. I.. Morfologia de sementes, de plântulas e da germinação de Copaifera langsdorfii Desf. (Leguminosae-Caesalpinioideae). Cerne, v.12, n.4, p.322-328, 2006.

JANSEN, L. L.; CRONIN, E. H.. Halogeton on trial, Farm and Home Science. Ogden, v.14, n.2, p.38-39, 1953.

LORENZI, H.. Árvores brasileiras: manual de identificação e cultivo de plantas arbóreas nativas do Brasil. 3 ed. Nova Odessa: Plantarum, 2009.

MAGUIRE, J. D.. Speed of germination-aid in selection and evaluation for seedling emergence and vigor. Crop Science, v.2, n.1, p.176-177, 1962.

MANDIĆ, V.; TOMIĆ, Z.; KRNJAJA, V.; BIJELIĆ, Z.; ŽUJOVIĆ, M.; SIMIĆ, A.; PRODANOVIĆ, S.. Effect of acid stress on germination and early seedling growth of red clover. Biotechnology in Animal Husbandry, v.27, n.3, p.1295-1303, 2011. DOI: http://doi.org/10.2298/BAH1103295M

NEVES, I. S.. Atributos do solo sob áreas de preservação permanente no bioma amazônico. Dissertação (Mestrado em Biodiversidade e Agroecossistemas Amazônicos) Universidade do Estado de Mato Grosso, Alta Floresta, 2018.

PAIVA SOBRINHO, S. P.; SIQUEIRA, A. G.. Caracterização morfológica de frutos, sementes, plântulas e plantas jovens de mutamba (Guazuma ulmifolia Lam, - Sterculiaceae). Revista Brasileira de Sementes, v.30, n.1, p.114-120, 2008. DOI: http://doi.org/10.1590/S0101-31222008000100015

PEREIRA, C. E.; PINHO, É. V. R. V.; OLIVEIRA, D. F.; KIKUTI, A. L. P.. Determinação de inibidores da germinação no espermoderma de sementes de café (Coffea arabica L,). Revista Brasileira de Sementes, v.24, n.1, p.306-311, 2002. DOI: http://doi.org/10.1590/S0101-31222002000100042

R DEVELOPMENT CORE EQUIPE. R: A Language and Environment for Statistical Computing, R Foundation for Statistical Computing, Vienna: R DEVELOPMENT, 2020.

RODRIGUES, R. S.; MATTOS, H. B.; PLESE, L. P. M.; PEREIRA, W. L. M.; BRENNECKE, K.. Calagem e disponibilidade de nutrientes após a incubação de um neossolo quartzarêmico. Boletim de Indústra Animal, v.61, n.1, p.31-38, 2004.

SHOEMAKERL, C. A.; CARLSON, W. H.. pH Affects Seed Germination of Eight Bedding Plant Species. Hortscience, v.25, n.7, p.762-764, 1990. 
SILVA, R. B.; MATOS, V. P.; FARIAS, S. G. G. L.; SENA, H. M.; SILVA, D. Y. B. O.. Germinação e vigor de plântulas de Parkia platycephala Benth. em diferentes substratos e

temperaturas. Revista Ciência Agronômica, v.48, n.1, p.142150, 2017. DOI: http://doi.org/10.5935/1806$\underline{6690.20170016}$

TUDELA-ISANTA, M.; LADOUCEUR, E.; WIJAYASINGHE, M.; PRITCHARD, H. W.; MONDONI, A.. The seed germination niche limits the distribution of some plant species in calcareous or siliceous alpine bedrocks. Alpine Botany, v.128, n.1, p.83-95, 2018. DOI:

http://doi.org/10.1007/s00035-018-0199-0

ÜNLÜ, H.; ÜNLÜ, H.; KARAKURT, Y.; PADEM, H.. Nitrogen and calcium concentration affect germination and seedling growth in pepper (Capsicum annuum L.). Erciyes Üniversitesi Fen Bilimleri Enstitüsü Dergisi, v.26, n.3, p.270-282, 2010.
VANZOLINI, S.; ARAKI, C. A. S.; SILVA, A. C. T. M.; NAKAGAWA, J.. Teste de comprimento de plântula na avaliação da qualidade fisiológica de sementes de soja. Revista Brasileira de Sementes, v.29, n.2, p.90-96, 2007. DOI: http://doi.org/10.1590/S0101-31222007000200012

VARGAS, J. P. R.; SANTOS, D. R.; BASTOS, M. C.; SCHAEFER, G.; PARISI, P. B.. Application forms and types of soil acidity corrective: Changes in depth chemical attributes in longterm period experimente. Soil \& Tillage Research, v.185, n.1, p.47-60, 2019. DOI: http://doi.org/10.1016/i.still.2018.08.014

YAMAUTI, M. S.; PAVANI, M. C. M. D.; ALVES, P. L. C. A.; MORO, F. V.. Efeito de fatores ambientais sobre a germinação de agriãozinho (Synedrellopsi risebachii). Científica, v.40, n.2, p.150-155, 2012. DOI: http://dx.doi.org/10.15361/1984-5529.2012v40n2p150+$+155$

A CBPC - Companhia Brasileira de Produção Científica (CNPJ: 11.221.422/0001-03) detém os direitos materiais desta publicação. Os direitos referem-se à publicação do trabalho em qualquer parte do mundo, incluindo os direitos às renovações, expansões e disseminações da contribuição, bem como outros direitos subsidiários. Todos os trabalhos publicados eletronicamente poderão posteriormente ser publicados em coletâneas impressas sob coordenação da Sustenere Publishing, da Companhia Brasileira de Produção Científica e seus parceiros autorizados. Os (as) autores (as) preservam os direitos autorais, mas não têm permissão para a publicação da contribuição em outro meio, impresso ou digital, em português ou em tradução. 